\title{
Rock pressure relief is the basic alternative for sustainable underground mining
}

\author{
Victor Nazimko ${ }^{1}$, Ludmila Zakharova ${ }^{1}$, Alexey Kusen ${ }^{1 *}$, and Syd Peng ${ }^{2}$ \\ ${ }^{1}$ Institute for Physics of Mining Processes NAS Ukraine, Ground Control Department, 95000 Str. Simferopolska, 14, Dnipro, Ukraine \\ ${ }^{2}$ West Virginia University, Mining Department, 1374 Evansdale Drive, 26506-6070, Morgantown, USA
}

\begin{abstract}
Retreat longwall mining is the most productive system for underground extraction of tabulated deposits. However, the steady growth of the mining depth dramatically increased the ground pressure in chain pillars protecting the longwall entries. Therefore, several coal industries have tried to shift to pillarless mining and practiced maintenance of the head or tail entry behind the longwall in the stress relief zones using the backfill bodies in the thin coal seams. We modernized the pillarless variant of the retreat longwall system introducing the third roadway, which is driven in the consolidated goaf behind the moving longwall in a stress relief zone. We used a computer code FLAC3D to simulate stress redistribution during pillarless extraction of adjacent panels that assisted to determine optimal parameters of mining layout. This modernized technology provides for sustainable mining due to enhancement of transport, ventilation, safety conditions, and a comfortable environment because of the stability of the underground roadways, which serve the high productive longwalls.
\end{abstract}

\section{Introduction}

Shallow reserves of energy resources have depleted since the middle of the twentieth century. The depth of mining has increased steadily that was followed by the intensifying of the ground pressure. For example, the average depth of the underground coalmines in Europe exceeded $700 \mathrm{~m}$. Several mines in Ukraine and China extract the coal at the depth of $1000 \mathrm{~m}$ and even more, which increased severe ground pressure manifestations such as gas, coal, and rock bursts, and spontaneous coal combustion. Also, the growing ground pressure augmented the problem of the underground roadway maintenance deteriorating its stability radically [1]. The worst of all is that the aforementioned problems have worsened sharply and unexpectedly.

The reason lies in a nonlinear response of underground roadways to the ground pressure raise [2]. Specialists in geomechanics use a simple but reliable empirical indicator that is a ratio $k$ of the vertical stress component of ground pressure $\sigma_{v}$ to unconfined compression strength (UCS) $\sigma_{c}$ :

$$
k=\sigma_{v} / \sigma_{c}
$$

If $k>0.33$ then the stability of an underground roadway fails dramatically since the convergence of the roof to floor and between sides of the roadway increases abruptly. Furthermore, the rate of convergence increment develops as the $k$ exceeds 0.33 .

The underground roadways present the main part of the underground mine fixed assets. Therefore, their deterioration dramatically inflates the total cost of extracted mineral resources. Meantime, world coal extraction has steadily grown because the demand for minerals and coal particularly raises.

Therefore, the task of maintaining the underground roadways' stability at the great depth has become a challenge.

The purpose of this presentation is to develop a prospective longwall technology using the maintenance of the roadways in the stress relief (SR) zones. In the second paragraph, we outlined the methods for the investigation of ground pressure redistribution during the pillarless panel extraction. Analysis of the traditional chain pillars system and substantiation of a new system using the third extra roadway has been described in the third paragraph. Then we investigated ground pressure redistribution during pillarless panels' expansion that helped to determine optimal parameters of the novel mining layout. Finally, the advantages of the new system have been discussed and the main conclusions outlined.

\section{Methods}

We used methods of computer simulation to investigate stress distribution and ground deformation around underground workings. The finite element algorithm (FEA) and finite difference methods are the most powerful and popular techniques, which are employed to solve complex problems when the stress-strain state of the rock mass should be investigated regarding nonlinear behaviour of the rocks and especially processes of their damage [3]. FEA successfully has been used during simulation of hydro-fracturing of the rock mass by SC-

\footnotetext{
* Corresponding author: kusenab@gmail.com
} 
$\mathrm{CO}_{2}$ mixture [4], fluid dynamic simulation [5], induced microseismicity by hydro-fracking [6], modelling of fracturing processes in discontinuous, porous rock masses [7].

The finite difference methods (FDM) are even more sophisticated for the simulation of geomechanical processes [8]. Alghalandis used FDM to improve discrete fracture network engineering [9], Bouzeran et al. simulated ground support performance in highly fractured and bulked rock masses [10], Bai et al. conducted numerical investigations of gateroad system failure induced by hard roofs in a longwall top coal caving face [11]. That is why we employed FLAC3D commercial code to simulate underground roadways behaviour in deep coalmines [12].

FLAC3D uses the explicit calculation cycling that propagates perturbation from an unbalanced force damping equations of motion that simulates dissipation of kinetic energy, Also, Cundall and Strack proposed an approach [13], when the calculation of motion (Newton second law) was solved ahead of the constitutive equation describing the stress-strain relation, including nonlinear behaviour of the rock. This imitated the real physics because the velocity of a disturbance wave is always limited in solid and liquid. This approach has provided success in preventing numerical instability and reproducing a realistic path of loading during simulation of nonlinear behaviour of the rock mass.

We also used physical modelling of irreversible ground movement to investigate the redistribution of ground pressure during consequent extraction of coal seams with longwall faces. Synthetic material that simulated a rock mass was a mixture of fine sand with plaster and mica.

Actual measurements of ground movement and deformation provided final and the most reliable data for confirming the results of computer simulation and physical modelling.

\section{Chain pillar technology and its alternative}

The longwall technology is the most popular in underground mining of tabulated deposits because of its exceptional economic efficiency. The majority of the coal reserves are extracted by retreat longwalls because the advanced longwall movement envisages driving the entries behind the moving face. In other words, the advanced longwall face moves blindly, which exposes it to the risk of impact with an unforeseen geologic fault.

A chain pillar system has been successfully used in US and Australia coalmines during the longwalls retreating since the middle of the last century to mine coal at a shallow and average depth (Fig.1). Longwall panel is outlined with at least two head entries 1 and 2 and tail entries 3 and 4 . The head and tail entries are periodically connected with crosscuts 5. Longwall face 6 moves in Fig. 1 to the right as indicated by empty arrow and remains behind itself an empty waste area or goaf 7 .

To provide safety, longwall 6 is ventilated by fresh air stream indicated by solid arrows. Mixture of air and methane/carbon oxide is removed through tail entry 4 as is indicated by intermitted arrows.

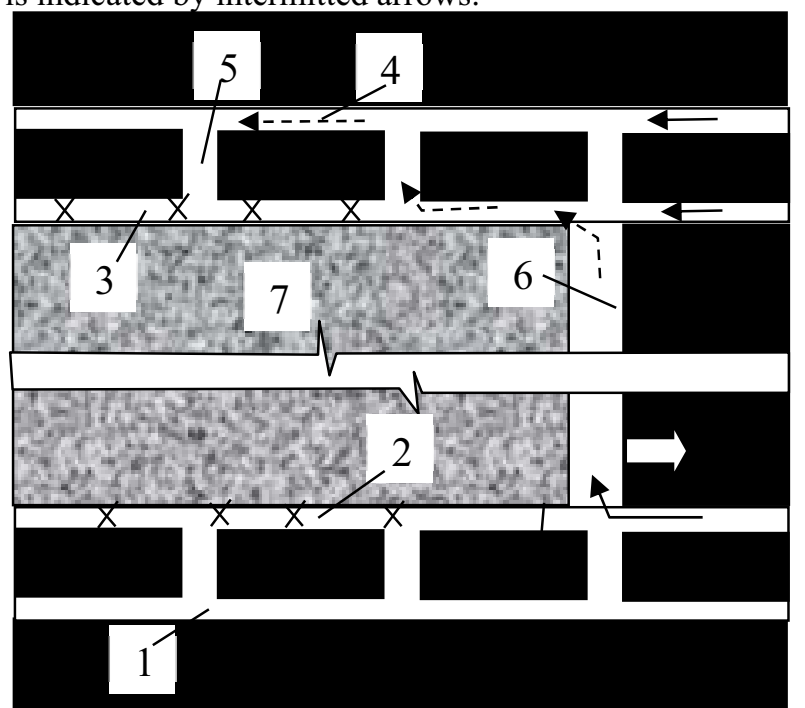

Fig. 1. Layout of the chain pillar system during the first longwall retreat: 1, 2 - head entries; 3, 4 - tail entries; 5 - crosscuts; 6 longwall face that moves in direction indicated by the empty arrow; 7 - goaf; solid arrows indicate the stream of fresh air whereas intermitted arrows show the movement of the air and methane mixture; crosses specify uncontrolled parts of entries

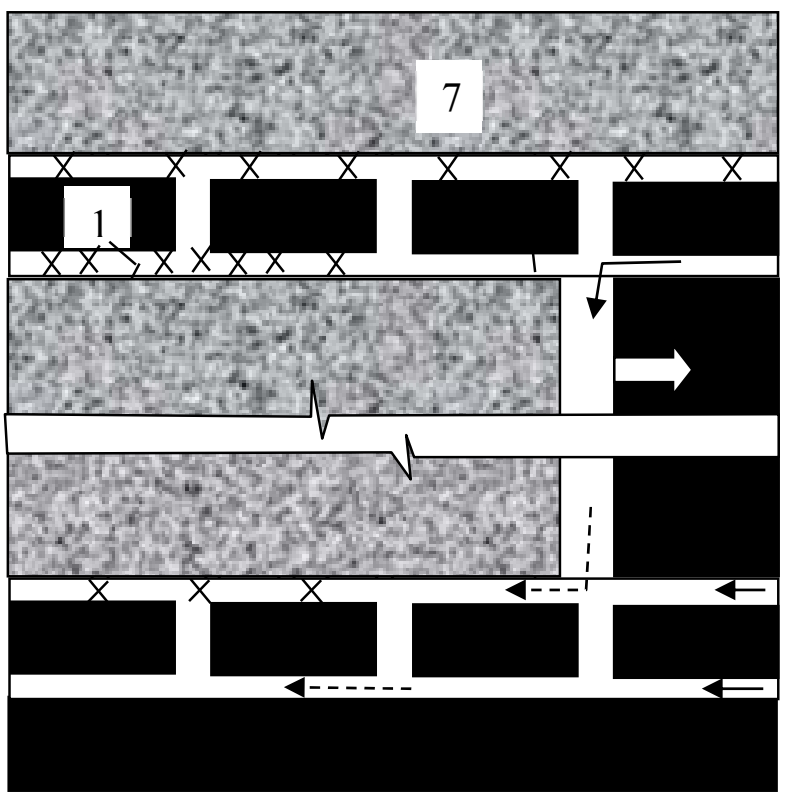

Fig. 2. Layout of the chain pillar system during the next adjacent panel extraction; numerals and arrows indicate the same positions as in Fig. 1

The ground pressure destroys head entry 2 and the crosses indicate an uncontrolled part of tail entry 3 behind the longwall. The next adjacent panels are extracted reusing head entry 1 as a tail entry (Fig. 2).

The content of the dangerous coal methane or carbon dioxide increases coherently with the growth of the depth that raises the probability of rock and coal bursts. That is why practitioners prefer to use Y-shape ventilation system, which provides moving both fresh air and a mixture of air and methane in the same direction as is indicated in Fig. 1. Opposite to the face advance, codirected movement of the air and contaminated gases pushes the dangerous gases out of longwall face and drifts 
them to the depth of the goaf promoting safety. This system envisages maintenance of the head entry behind the moving longwall where intensive ground pressure causes extensive damage to the roadway. The chain pillars are remained behind the longwall to eliminate this negative effect of the ground pressure.

The idea of the chain pillar technology was based on reusing the head entry 1 , which is extreme relatively the goaf boundary. This entry is used again during mining the next adjacent panel (Fig. 2). The head entry, which was close to the goaf boundary, is destroyed after the extraction of coal in the previous panel. However, the extreme head entry ought to be saved and reused as a tail entry for the next panel.

All entries in the chain pillar system are maintained in abutment zones, which concentrate ground pressure and deteriorate the entries. Therefore the more depth of mining the more intensive the abutment pressure is. This situation demands to increase the width of the chain pillars but enlarging the pillars' dimension does not help essentially because of the high overall level of the ground pressure. For example, the index $k$ of the roadway stability increases up to $0.5>0.33$ at the depth of $800 \mathrm{~m}$ and UCS of $40 \mathrm{MPa}$.

That is why a relevant area of the chain-pillar system implementation is limited by $450-500 \mathrm{~m}$. In other words, the steady growth of the mining depth dramatically increased the ground pressure and excessively wide chain pillars become unacceptable. Therefore, several coal industries, for example, Chinese and Ukrainian have tried to shift to pillarless mining [15] and practiced maintenance of the head or tail entry behind the longwall [14].

US regulations forbid driving of a single underground roadway due to certain ventilation risks. However, European and Asian countries allow such driving. This circumstance made it possible to get rid of the chain pillars and apply $\mathrm{Y}$-shaped ventilation system. In order to do this, the head goaf-side entry 2 was retained behind the longwall face using a roadside backfill body [16], [17], or an artificial wall [14] (Fig. 3).

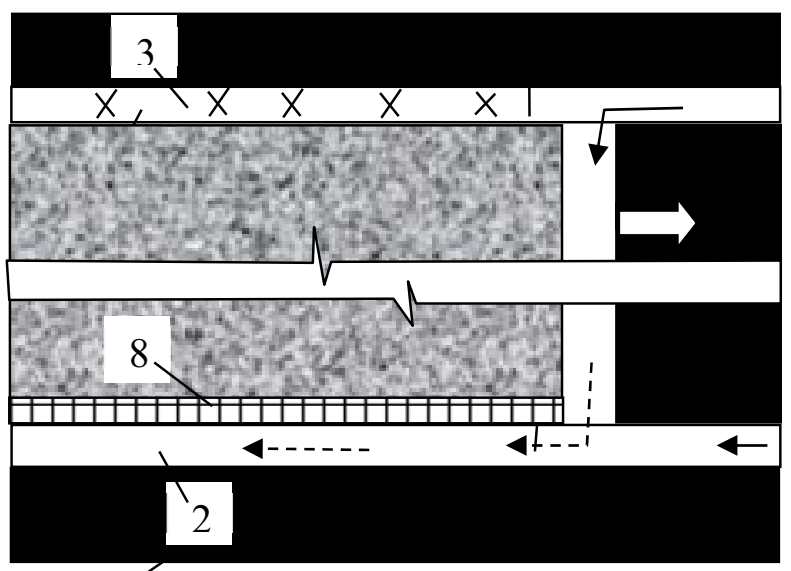

Fig. 3. Mining design with the artificial wall 8

Designers conceive to maintain the head entry with the cement backfill body, which should save stability and integrity during its reusing in the course of the next panel extraction as is shown in Fig. 4.
Reusing the head entry during pillarless mining is a very attractive idea because it saves labour, materials, and energy. However, as far as we know, a successful experience of reusing the head entry, which was driven before the longwall extraction and retained behind this longwall has not been published. Furthermore, several authors emphasize that even retaining and maintenance of an entry behind the advancing (not retreating) longwall is not an easy task at a great depth [16], [19], [18]. That is why the artificial wall technology has been enhanced by a roof cutting to relieve stress at the goaf side [20], [21].

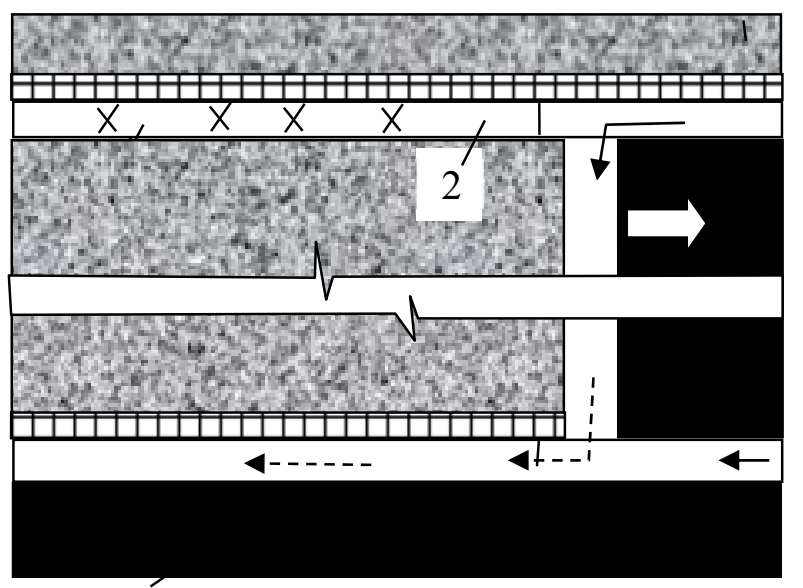

Fig. 4. Mining of an adjacent panel reusing head entry 2

Feng and Wang [22] described an original innovative technology of SR. The entry was planned to be driven under the goaf edge employing split-level longwall panel layout. However, such a system is relevant for the thick coal seams having the height, which exceeds more than two heights of the gateways.

\section{Investigation of ground pressure evolution during pillarless mining}

SR formation around the roadways has a long history and tradition. We consider the most popular technologies, which have proven their efficiency in the mining practice. Analysing any SR technology we should keep in mind that the relief from the high level of stress is inextricably linked up with a yielding. To get certain unloading from the ground pressure we should be ready to provide some deformation, which will reduce the area of a roadway section.

Zhan et al. [14] investigated a retained goaf-side tail entry, which has been maintained by means of building the artificial wall along the goaf side when the longwall face advanced. The roof of the roadway was reinforced by rock bolts and long 5-metre cables having a total bearing capacity of more than $400 \mathrm{kN} / \mathrm{m}^{2}$. Despite this, the roof of the entry subsided to $500 \mathrm{~mm}$ whereas the floor heaved up to $1700 \mathrm{~mm}$, which deteriorated the roadway section unacceptably when the longwall face had moved a considerable distance. Therefore, the entry has been repaired to a large extent.

The integrity of the artificial wall was checked, and the cracks and fissures on the wall surface were filled to 
prevent water and gas in the goaf area from flowing into the roadway space during maintenance.

The floor was dinted to recover the working space for the following operations. This made it possible to remove the squeezed part of the coal side of the roadway. As a result, initially installed rock bolts and cable bolts were exposed due to the widening of the entry. The extra ends of the bolts and cable were cut off, and the retained portion inside the surrounding rock was prestressed again.

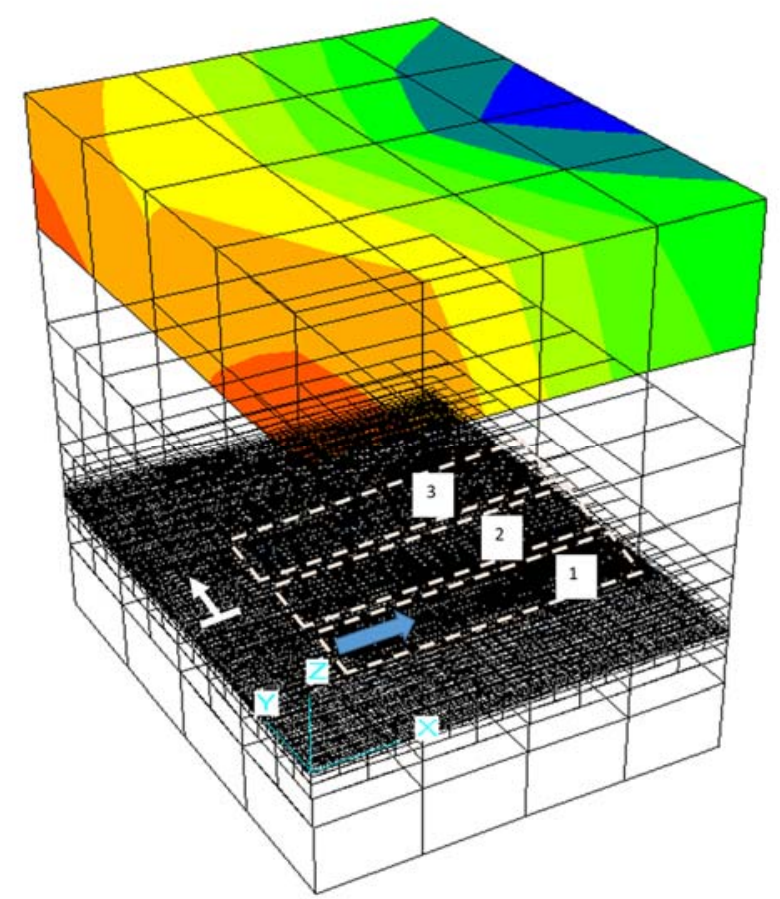

Fig. 5. Layout of the model; numbers indicate the sequence of panels extraction.

According to [14] the roadway section has been recovered and satisfied the requirements of the adjacent panel excavation. However, there was no information concerning the experience of this important part of mining. Pillarless extraction of a panel adjacent to a previously formed goaf causes an extensive ground pressure intensification there, which inevitably will worsen ground control and maintenance of the roadway. To investigate this process, we have carried out a computer simulation of the ground pressure redistribution during adjacent panels' extraction.

Fig. 5 demonstrates the layout of three panels extraction without abandoning inter-panel pillars. The vertical dimension of the model was $1500 \mathrm{~m}$ and a flat 1.5 -meter coal seam was at the depth of $1100 \mathrm{~m}$. The dimension of the model along the strike (axis $\mathrm{X}$ ) was $1024 \mathrm{~m}$ and alongside with the dip (axis Y) $1240 \mathrm{~m}$. The direction of the panel retreat is indicated by the fat arrow. Every panel had a width of $256 \mathrm{~m}$ and located relatively model boundaries at $256 \mathrm{~m}$. The step of the longwall retreat was $10 \mathrm{~m}$ that was moving at the rate of $250 \mathrm{~m}$ per month.

We used Mohr-Colomb law as the constitutive model of the rock mass. We also accounted for the process of softening due to the rock damaging involving elements of
Hoek-Broun empirical rules. The cohesion of the rock dropped down to $1.0-0.5 \mathrm{MPa}$ when dilation strain reached up to 0.004 .

The thickness and mechanical properties of the rocks are presented in Table 1, and Fig. 6 shows the vertical movement of the rock mass after extraction of the first panel. Geologic and geomechanical conditions describe those, which were at a typical deep coal mine 'Pocrovs'ke' in Ukraine.

Table 1. Properties of the rock layers in the model

\begin{tabular}{|c|c|c|c|c|c|c|c|}
\hline Rock & 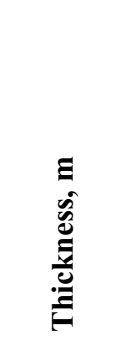 & 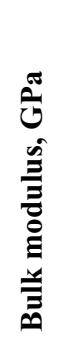 & 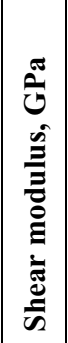 & 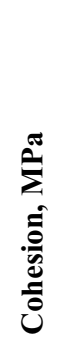 & 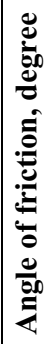 & 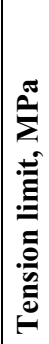 & 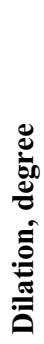 \\
\hline Rock & $\begin{array}{c}\text { Cover \& } \\
\text { Base }\end{array}$ & 14.0 & 8.4 & 9.0 & 35 & 7.0 & 10 \\
\hline Sandstone, roof & 20.0 & 24.0 & 14.4 & 12.0 & 28 & 9.0 & 9 \\
\hline $\begin{array}{l}\text { Shale, immediate } \\
\text { roof }\end{array}$ & 10.0 & 14.0 & 8.4 & 7.0 & 28 & 5.0 & 10 \\
\hline Coal & 1.5 & 14.0 & 8.4 & 7.0 & 28 & 4.0 & 11 \\
\hline $\begin{array}{l}\text { Shale, immediate } \\
\text { floor }\end{array}$ & 10.0 & 14.0 & 8.4 & 9.0 & 28 & 5.0 & 10 \\
\hline Shale, floor & 20.0 & 14.0 & 8.4 & 12.0 & 35 & 9.0 & 10 \\
\hline
\end{tabular}

Elastic recovery of the floor was $40 \mathrm{~cm}$, which is close to $34 \mathrm{~cm}$ registered in situ using levelling at the depth of $915 \mathrm{~m}$. This simulation has been conducted in 'set large' displacement mode, which envisages recalculation of the node coordinates according to current increment of the displacements.

Fig. 7 demonstrates the distribution of the vertical stress component around the goaf of the first panel. Average vertical stress in the goaf does not exceed $8 \mathrm{MPa}$ that 3.36 times less than geostatic level, which was $27 \mathrm{MPa}$.

Furthermore, the stress diminished down to $3 \mathrm{MPa}$ in the immediate vicinity of the goaf border 1 that is nine times less than the geostatic level.

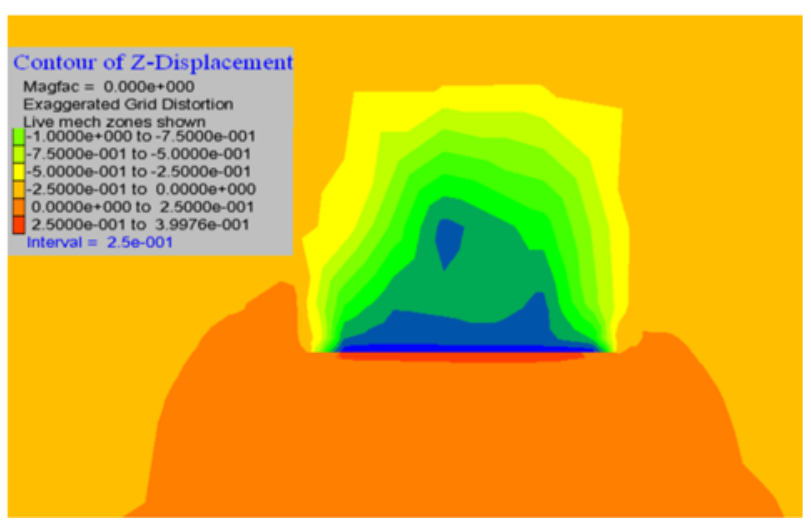

Fig. 6. Contour of the vertical displacement after the first panel extraction. 


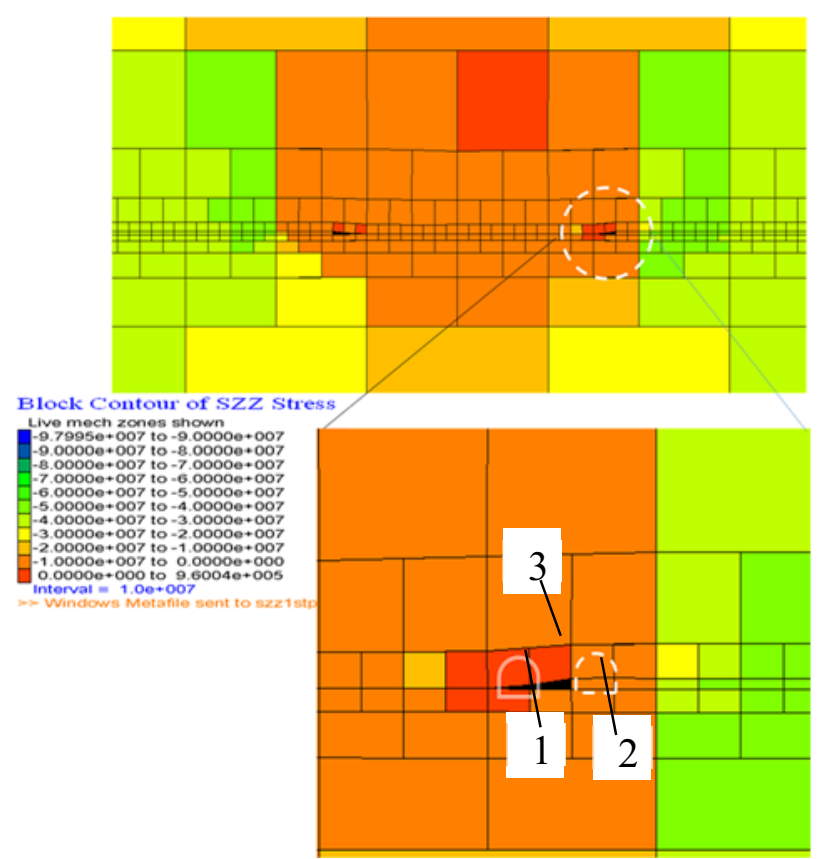

Fig. 7. Distribution of the vertical component of the ground pressure after the first-panel mining.

Position 2 in Fig. 7 indicates the edge of the coal seam that is adjacent to the goaf boundary 3. This area was essentially relieved of the ground pressure reducing it down to $10 \mathrm{MPa}$. Therefore, miners drive the roadways in the aforementioned area that got traditional characteristics as 'skin-to-skin' driving.

Roadway 1 is in a highly favourable position because of an extremely low surrounding stress. Such roadways have been driven in the goaves of Ukrainian coalmines since $1960^{\text {th }}$. SR zones attracted practitioners to place the roadways in the goaves (Fig. 8). The stability of these gateways was excellent for a long period while the goaf boundary was fixed. However, the roadway state has worsened as an adjacent to the boundary panel was mined. Therefore, we should examine the case when the adjacent panel will be extracted.

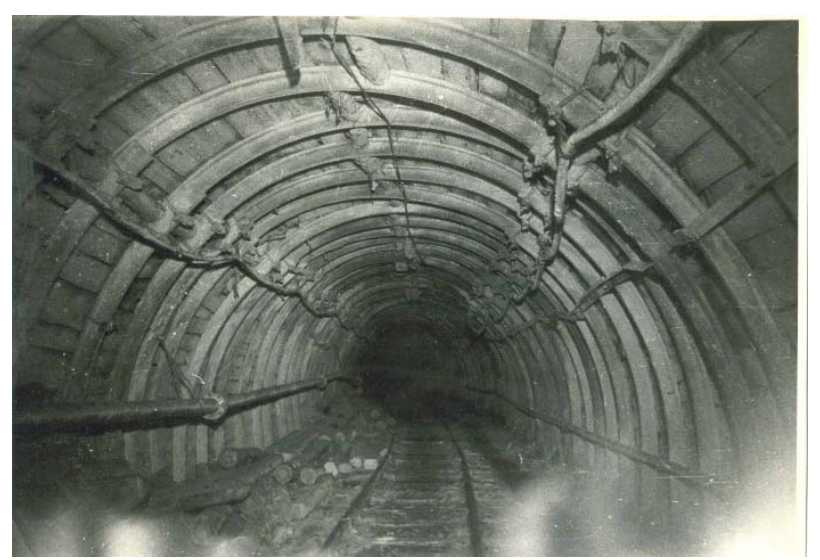

Fig. 8. An example of good stability of a roadway driven in compacted and consolidated goaf.

Fig. 9 demonstrates that pillarless extraction of the adjacent panel reduced SR in the goaf of the previous panel. For example, ground pressure in the goaf after extraction of panel 2 was approximately $12 \mathrm{MPa}$.
However, pillarless extraction of the third panel essentially increased the stress in the goaf of the second panel. The vertical stress in goaf 2 increased up to $22 \mathrm{MPa}$ that raised k-index up to $0.55>0.33$ (Fig. 9), which has worsened the ground pressure background regarding the roadway stability.
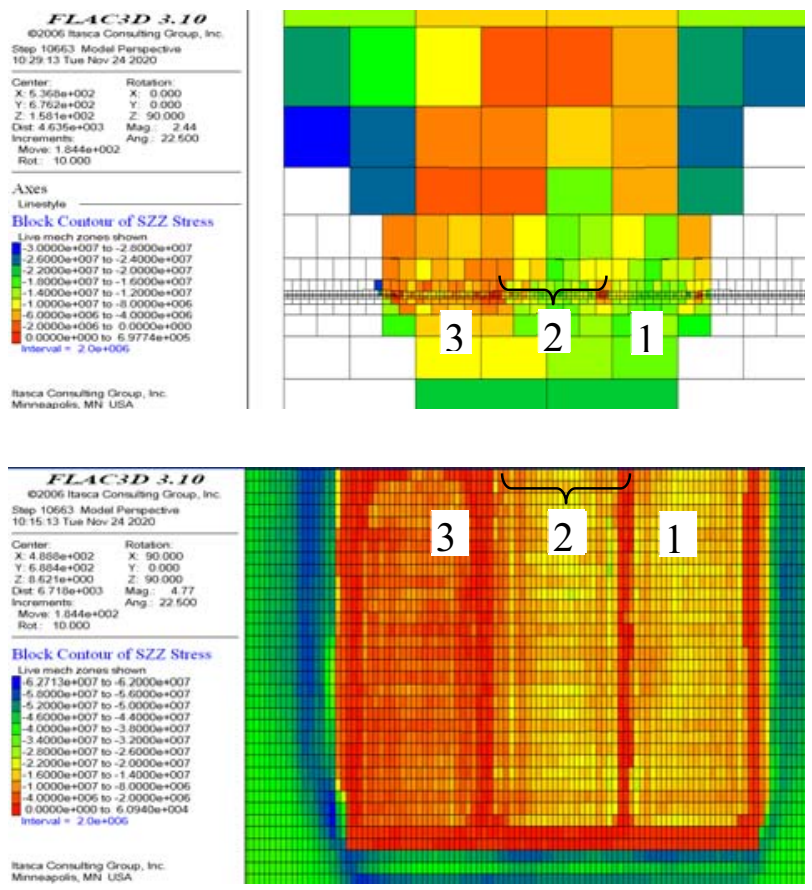

Fig. 9. Stress distribution after extraction of all three panels: vertical section (top); plan view (bottom).

Fig. 10 demonstrates as the k-index evolved during the expansion of mining. Stages from 0 to 2 correspond to the extraction of the current panel whereas stages from 2 to 5 describe the situation when the next (adjacent) panel was extracted.

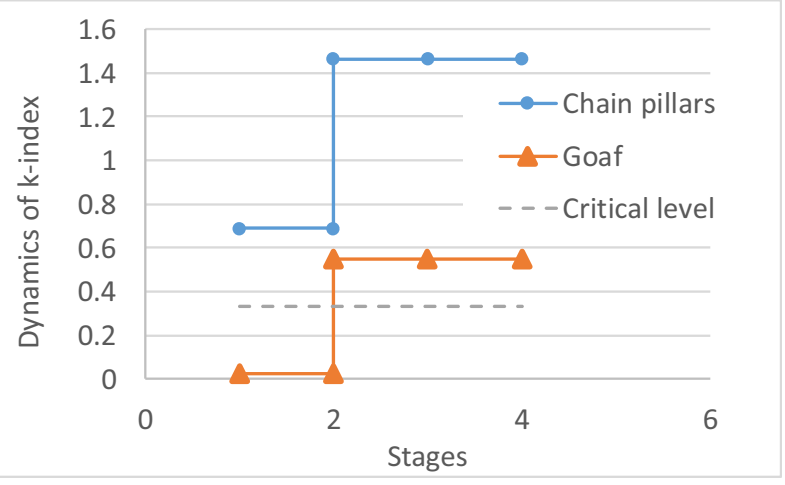

Fig. 10. Evolution of k-index during the extraction of the panels.

The driving and maintenance of the roadway in a goaf is much more favourable than the maintenance of the entries by the chain coal pillars because the ground pressure is less by 30 times behind the current panel and by 2.66 times less after the adjacent panel mining. However, despite this advantage, the roadway in the goaf will suffer because the k-index exceeded the critical level of 0.33 . 


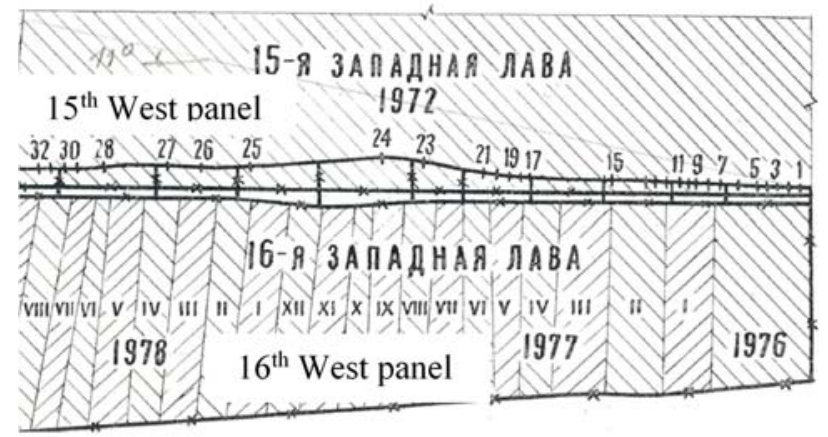

Fig. 11. Mining layout with the third entry drove in a goaf of $l_{4}$ coal seam.

The results of the computer simulation have been proven by an experiment in situ (Fig. 11). West panel \#16 extracted the flat 1.6-meter coal seam $l_{4}$ at the depth of $720 \mathrm{~m}$ (the coal mine named after Abakumov, Donetsk, Ukraine) [23]. Weak mudstone having UCS of 20$30 \mathrm{MPa}$ and thickness of $10 \mathrm{~m}$ represented the immediate roof whereas medium-strength sandstone deposited in the main roof. Shale with UCS of $30-40 \mathrm{MPa}$ bedded in the immediate floor.

The third entry was driven in 1975 through the goaf of the $15^{\text {th }}$ West panel, which was extracted in 1972. The convergence of the roof and floor in the experimental entry has been periodically measured at the stations indicated by numbers from 1 to 32 . Panel \#16 was extracted by a longwall with the rate of $30-40 \mathrm{~m} / \mathrm{month}$. Roman numbers on the layout in Fig. 11 indicate the month advances.

We selected the monitoring stations from 17 th to 20 th for demonstration of the third entry reaction to the West longwall \#16 retreating. These stations were sufficiently far from the start-up room and reflect a typical periodic roof caving during longwalling.

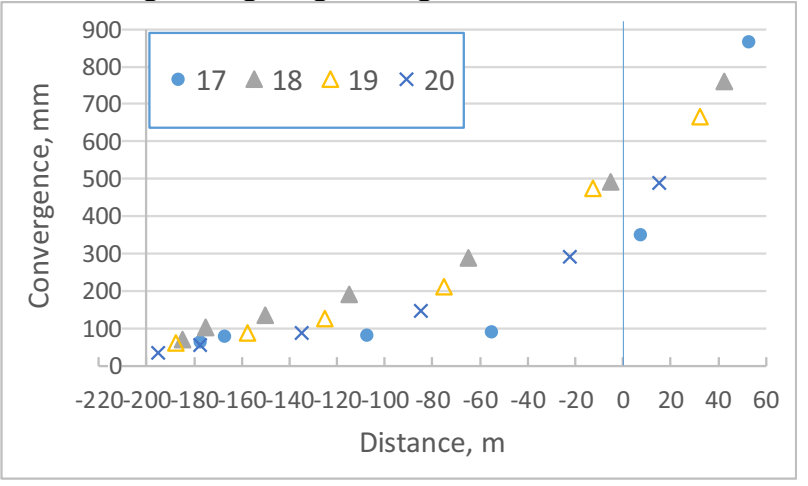

Fig. 12. Results of the convergence monitoring in the third entry.

The negative distance in Fig. 12 points to the position of the monitoring stations before the approaching longwall (outby) whereas positive values of the distance indicate that the longwall passed by the station and moves away from it. The third entry has not been maintained behind the longwall (inby) but there was a possibility to continue the monitoring inby it some period. Fig. 12 shows there was not a subsiding tendency. Furthermore, the convergence had approached up to $0.8 \mathrm{~m}$ and steadily continued to grow.

Therefore, additional means are necessary to protect the roadway in the goaf from the negative influence of the adjacent panel mining. The most technological means is the backfill body [24], [25] (Fig. 13).

Roadway 9 is driven behind the longwall. The face of roadway 9 lags to prevent the negative impact of the ground subsidence behind the moving longwall. Distance D should protect the roadway stability and secure that it will be driven in a completely consolidated goaf.

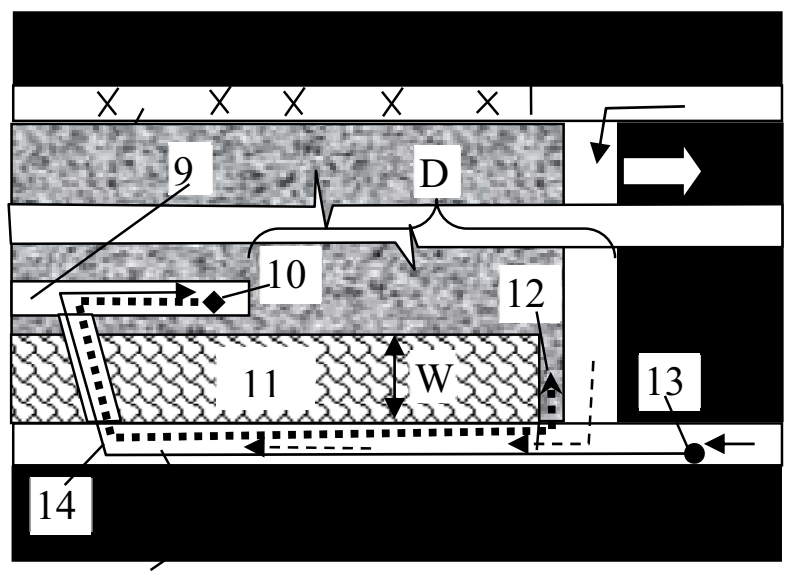

Fig. 13. Mining layout during driving of the roadway 9 in the goaf of the first (previous) panel; 10 - conveyor chain for transportation of the waste rock for the filing of the back body $11 ; 12$ - pneumatic discharge of the crashed waste rock; 13,14 - local fan and flexible tube for the roadway face ventilation; D - lag distance of the roadway 9 from the longwall.

The waste rock from the driving of roadway 9 is removed by conveyor chain 10 , ground by crusher, and packed to the backfill body 11 with pneumatic machine 12. The building of body 11 from the waste rock is viable economically and friendly ecologically. Width $W$ of the backfill body 11 is proportional to the section area of roadway 9 and diminishes as the coal seam height increases. For example, $\mathrm{W} \approx 25 \mathrm{~m}$ when the net roadway section is $20 \mathrm{~m}^{2}$ and the height of the coal seam is $1.5 \mathrm{~m}$.

Fan 13 ventilates roadway 9 with fresh air, which is collected in front of the longwall face.

Lag $D$ of the roadway face depends on the rate of the longwall retreating. For the depth of $1100 \mathrm{~m}$ and the rate $300 \mathrm{~m} /$ month $D=245 \mathrm{~m}$ (Fig. 14). Such a distance guarantees a perfect stability of the roadway 9 because it will be driven in the consolidated goaf out of active subsidence of the undermined strata.

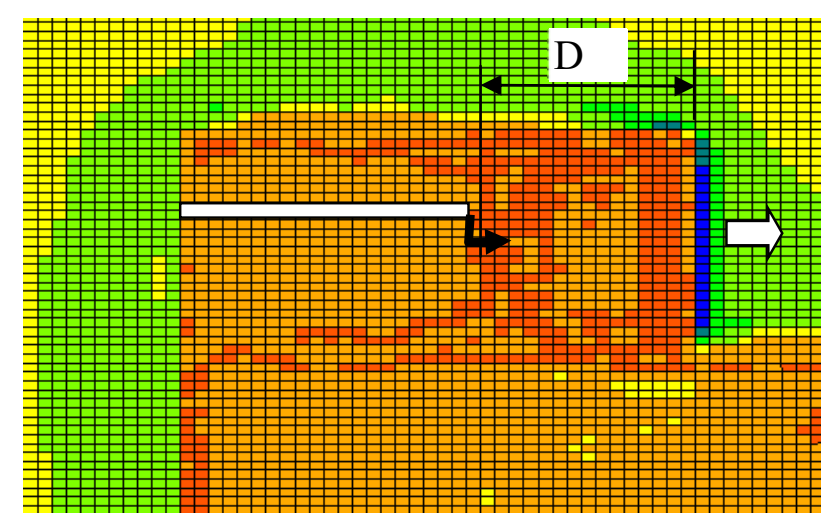

Fig. 14. Distribution of the ground pressure in the goaf behind the moving longwall face. 
Fig. 15 shows layout of the mining works during the adjacent panel extraction.

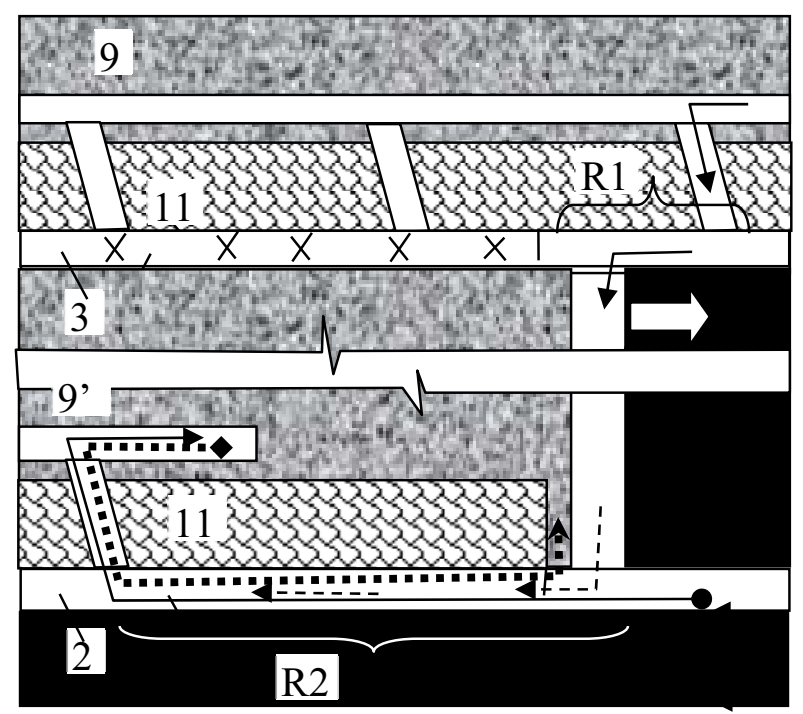

Fig. 15. Mining layout during adjacent panel extraction

This layout has an essential advantage over the chain pillar system. There is no need to maintain entries 2 and 3 through the whole length. It will be sufficient to retain entry 3 between the moving longwall face and the forward crosscut (interval R1), and entry 2 between the longwall and the closest rear crosscut (interval R2). General main service for mining operations will be provided by the roadway 9 and 9': entry 9 will provide the longwall for fresh air and transportation of the coal whereas entry 9' will remove the mixture of air and methane. This is the best variant \#1 from the technical point of view and safety consideration.

There is another option \#2 when the fresh air stream moving along the longwall reverses its direction, namely goes from the bottom to the top. In this situation, entries 9 and 9' swop their functions but entry 3 must be maintained behind (inby) the longwall, namely from the face to the closest rear crosscut that is not so easy task. Both roadways 9 and 9' will be in a stable state due to protection of the backfill bodies 11 that was demonstrated on the physical model (Fig. 16).

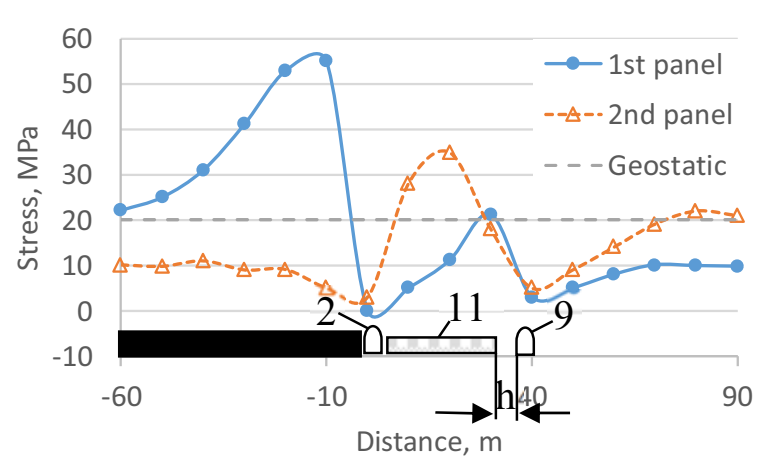

Fig. 16. Stress distribution after $1^{\text {st }}$ and $2^{\text {nd }}$ panel extraction.

The backfill body 11 creates local SR zones at the edges. These zones conserve SR that minimizes the ground pressure activation after the second (adjacent) panel extraction. That is why roadway 9 should be driven in the goaf immediately at the backfill body edge or at the distance $\mathrm{h}=5-6 \mathrm{~m}$ from it.

Mining practice has demonstrated that it is impossible to provide the ideal stability of entries 2 and 3 at the great depth of mining [26]. However, this is realistic to provide minimum means for retaining their intervals $\mathrm{R} 1$ and $\mathrm{R} 2$ if to use the arch shape of the entries and support them by a combination of yield frames, rock bolts, and cables. Then the dinting of the floor will be sufficient because the selfsupporting effect will stabilize the roof [27].

An economic assessment has demonstrated that extra cost of the third roadway driven in the goaf does not exceed $10 \%$ of the total profit from the increase of the coal output due to enhancement of transport, ventilation, safety conditions, and comfortable environment because of stability of the underground roadways serving the high productive longwalls.

\section{Conclusion}

Retreat longwall mining using the chain pillars has become popular in underground mining since the $1960^{\text {th }}$. However, the steady growth of the mining depth dramatically increased the ground pressure and excessively wide chain pillars become unacceptable. Therefore, several coal industries have tried to shift to pillarless mining and practiced maintaining the head or tail entry behind the longwall in the stress relief zones using the backfill bodies in the thin coal seams.

The mining experience has demonstrated so far that it is not easy to retain entries behind the longwall with the backfill bodies. We modernized the pillarless system introducing the third roadway, which is driven in the consolidated goaf behind the moving longwall and used as a tail entry.

The waste rock from the driving is ground and discharged by pneumatic equipment into the goaf. The backfill body is erected from the waste at hand material immediately behind the longwall face. This backfill support protects the roadway from the ground pressure activation during adjacent panel extraction and reusing of the roadway as a head entry.

The extra cost of the third roadway driven in the goaf does not exceed $10 \%$ of the total profit from the increase of the coal output owing to Y-shape ventilation system exploding. New technology provides for sustainable mining due to enhancement of transport, ventilation, safety conditions, and a comfortable environment because of the sufficient stability of the underground roadways, which serve the high productive longwalls.

The authors thank Donetsksteel Company that provided key $\mathrm{n}^{\circ} 024486$ for simulation on FLAC3D that is highly appreciated. There is no conflict of interest concerning the results of this paper.

This work was conducted within the grant of the National Academy of Ukraine (State registration No. 0120U100081). 


\section{References}

[1]. P. G. Ranjith et al., Engineering 3, 546-551 (2017) doi:10.1016/J.ENG.2017.04.024

[2].O.V. Solodyankin, O.Y. Hryhoriev, I.V. Dudka, \& S.V. Mashurka, Naukovyi Visnyk Natsionalnoho Hirnychoho Universytetu, (2), 19-27 (2017)

[3].L. Jing, International Journal of Rock Mechanics \& Mining Sciences, 40, 283-353 (2003) doi:10.1016/S1365-1609(03)00013-3

[4].S. Liu, A. Suzuki, \& T. Ito, International Journal of Rock Mechanics \& Mining Sciences, 132 (2020) doi:10.1016/j.ijrmms.2020.104385

[5].E. Papachristos et al., International Journal of Rock Mechanics \& Mining Sciences, 93, 163-178 (2017) doi:10.1016/j.ijrmms.2017.01.011 Minerals 2019, 9, 53; doi:10.3390/min9010053

[6]. J.A. Lopez-Comino et al., Geophys. J. Int. 210, 4255 (2017) doi: 10.1093/gji/ggx148

[7]. A. Lisjak et al., Computers and Geotechnics 81, 1-18 (2017) doi:10.1016/j.compgeo.2016.07.009

[8].M. Krzaczek M. Nitka, \& J. Tejchman, Numerical and Analytical Methods in Geomechanics, 45(2) 234-264 (2021) doi: 10.1002/nag.3160

[9]. Y. F. Alghalandis, Computers \& Geosciences 102, 111 (2017) doi:10.1016/j.cageo.2017.02.002

[10]. L Bouzeran et al., Eighth International Conference on Deep and High Stress Mining - J Wesseloo (ed.) Australian Centre for Geomechanics, Perth, 667-680, (2017) doi:10.36487/ACG_rep/1704_45_Bouzeran

[11]. Q. Bai et al., International Journal of Coal Geology 173 (2017) 176-199, doi.org/10.1016/j.coal.2017.02.015

[12]. FLAC3D Fast Lagrangian Analysis of Continua in 3 Dimensions. Itasca Consulting Group, Inc. Version 3.10.F. (2008)

[13]. P.A. Cundall, \& O. D. L. Strack, Geotechnique, 29 (1), 47-65 (1979)

[14]. N.C. Zhang et al., Int. J. Min. Reclam. Environ (2015), doi:10.1080/17480930.2015.1024814.

[15]. V.V. Nazimko, Proceedings of 14th Int. Conf. on Ground Control in Mining, August 2-4, 1994, Morgantown, WV, pp. 239-245 (1994)

[16]. Z. Zhang et al., International Journal of Rock Mechanics \& Mining Sciences, 126, 104184 (2020) doi:10.1016/j.ijrmms.2019.104184

[17]. W. Wu et al., Energy sources, part a: recovery, utilization, and environmental effects, doi:10.1080/15567036.2020.1747574

[18]. Q. Sun et al., Natural Resources Research (2019) doi:10.1007/s11053-019-09584-4

[19]. Y.L. Tan et al., International Journal of Rock Mechanics \& Mining Sciences, 77, 202-207 (2015) doi: 10.1016/j.ijrmms.2015.04.002

[20]. X. Chen et al., Energy Science and Engineering, (2020) doi : 10.1002/ese.3.648
[21]. X. Ma, Energies, 11, $2539 \quad$ (2018) doi:10.3390/en11102539

[22]. G. Feng \& P. Wang, International Journal of Mining Science and Technology, 131 (2020) doi:10.1016/j.ijrmms.2020.104349

[23]. V.V. Nazimko, Disertation, Donetsk Polytechnic Institute, 1981

[24]. J. Zhang et al., International Journal of Rock Mechanics \& Mining Sciences, 88, 197-205 (2016) doi: 10.1016/j.ijrmms.2016.07.025

[25]. J. Zhang et al., Minerals 9, 53 (2019), doi: $10.3390 / \min 9010053$

[26]. S. Hai et al., International Journal of Mining Science and Technology, 25, 503-510 (2015), doi: 10.1016/j.ijmst.2015.03.027

[27]. V.V. Nazimko, A.A. Lapteev, \& V.P. Sazhnev, International journal of rock mechanics and mining sciences \& geomechanics abstracts, 1997, 34(3-4), doi.10.1016/S1365-1609(97)00194-9 